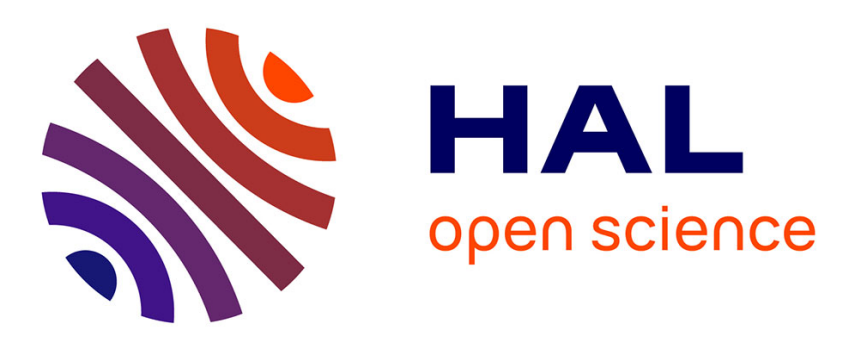

\title{
Landscape 'stress' and reorganization from chi-maps: Insights from experimental drainage networks in oblique collision setting
}

Laure Guerit, Liran Goren, Stephane Dominguez, Jacques Malavieille, Sebastien Castelltort

\section{To cite this version:}

Laure Guerit, Liran Goren, Stephane Dominguez, Jacques Malavieille, Sebastien Castelltort. Landscape 'stress' and reorganization from chi-maps: Insights from experimental drainage networks in oblique collision setting. Earth Surface Processes and Landforms, 2018, 43 (15), pp.3152-3163. 10.1002/esp.4477 . hal-01975947

\section{HAL Id: hal-01975947 \\ https://hal.science/hal-01975947}

Submitted on 6 Nov 2020

HAL is a multi-disciplinary open access archive for the deposit and dissemination of scientific research documents, whether they are published or not. The documents may come from teaching and research institutions in France or abroad, or from public or private research centers.
L'archive ouverte pluridisciplinaire HAL, est destinée au dépôt et à la diffusion de documents scientifiques de niveau recherche, publiés ou non, émanant des établissements d'enseignement et de recherche français ou étrangers, des laboratoires publics ou privés. 


\title{
Landscape "stress" and reorganization from $\chi$-maps: insights from experimental drainage networks in oblique collision setting
}

\author{
L. Guerit ${ }^{1, *}$, L. Goren ${ }^{2}$, S. Dominguez ${ }^{3}$, J. Malavieille ${ }^{3}$, S. Castelltort ${ }^{1}$ \\ ${ }^{1}$ University of Geneva, Department of Earth Sciences, 1205 Geneva, Switzerland \\ * now at: Géosciences Environnement Toulouse, 31400 Toulouse, France \\ 2 Geological and Environmental Sciences, Ben-Gurion University of the Negev, Beer Sheva 84105, \\ Israel \\ ${ }^{3}$ Université de Montpellier, Géosciences Montpellier UMR 5243, F-34095 Montpellier, France \\ correspondance to : laure.guerit@get.omp.eu
}

\section{Résumé}

Several recent studies have suggested that maps of flow length normalized for drainage area called chi $(\chi)$ could reveal landscapes in a transient state, which are prone for reorganizations of basin geometry, flow lines topology, and water divide locations. However, the potentially long timescales associated with the evolution of basin geometry make the capability of $\chi$ to predict such reorganization challenging to test in natural settings. Here, we investigate the evolution of experimental drainage networks developed on a wedge coupled to a piedmont and growing in oblique convergence. We use this experimental setting to investigate the relationships between $\chi$ maps, the imposed tectonic deformation and the drainage network evolution. As deposition can occur within channels or in the piedmont, our experimental streams deviate from purely bedrock channels for which the $\chi$ metric has been initially developed. Yet, we show that the large-scale $\chi$ pattern of the experimental drainage network is consistent with the imposed deformation field, as $\sim 2 / 3$ of the observed $\chi$ gradients across water divide are oriented in the expected direction with respect to the imposed deformation. This suggests that $\chi$ maps can be used to infer the horizontal component of regional deformation in large-scale natural mountainous fluvial landscapes. In addition, we observe that when a divide affected by a $\chi$ gradient migrates, the orientation of the gradient correctly anticipates the sense of landscape reorganization for $\sim 2 / 3$ of these divides.

\section{Introduction}

The morphology of fluvial landscapes reflects an equilibrium between their internal dynamics and external forcings (Brookfield, 1998; Wobus et al., 2006; Bishop, 2007; Kirby and Whipple, 2012), and many studies have explored the possibility of using fluvial drainage networks as recorders of the forcings that shaped a landscape. The capability of fluvial landscapes to record information about external forcings is rooted in the power-law relationship that has been documented for more than a century between the slope of a stream and its drainage area (e.g., Flint, 1974; Wobus et al., 2006). Assuming the commonly used stream power 
model (e.g., Howard and Kerby, 1983; Whipple and Tucker, 1999; Perron and Royden, 2013; Mudd et al., 2014; Lague, 2014), this relationship can be expressed as:

$$
\frac{d z}{d x}=\left(\frac{U}{K}\right)^{1 / n} A^{-m / n}
$$

where $d z / d x$ is the slope, $U$ is the vertical uplift rate $\left(\mathrm{L} \mathrm{T}^{-1}\right), K$ is the erodibility $\left(\mathrm{L}^{1-2 m} \mathrm{~T}^{-1}\right), m$ and $n$ are two positive, non-integer, powers and $A$ is the upstream drainage area $\left(\mathrm{L}^{2}\right)$. Based on Equation 1 , major focus has been cast on the relations between the long profiles of fluvial channels and rock uplift conditions (e.g., Lavé and Avouac, 2001; Clark et al., 2004; Pritchard et al., 2009; Brocard et al., 2011; Strak et al., 2011; Kirby and Whipple, 2012; Whittaker, 2012; Royden and Perron, 2013; Goren et al., 2014; Grosjean et al., 2015). So far, however, relatively few studies have investigated the possibility of inferring the tectonic deformation from the map-view pattern of drainage networks (Hallet and Molnar, 2001; Ramsey et al., 2007; Castelltort et al., 2012; Goren et al., 2015). Yet, when the crust deforms horizontally, the bedrock river network that is carved at its surface is expected to deform accordingly. Drainage networks could thus reveal information about the horizontal component of deformation (Hallet and Molnar, 2001; Ramsey et al., 2007; Castelltort et al., 2012; Goren et al., 2015).

Deformation of a channel network will potentially change the drainage area distribution and the local slope, and consequently, the river network will deviate from Equation 1. Willett et al. (2014) have postulated that violation of this power-law relationship, which can be understood as a non-equilibrium drainage area distribution and streamline topology, can be identified by observing $\chi$, a transformation parameter of distance along channel (Perron and Royden, 2013) that emerges from integrating Equation 1 along the river flow, from the base level $x_{b}$ to a point $x$ :

$$
z(x)=z\left(x_{b}\right)+\left(\frac{U}{K A_{0}{ }^{m}}\right)^{1 / n} \chi(x)
$$

with

$$
\chi(x)=\int_{x_{b}}^{x}\left[\frac{A_{0}}{A(x)}\right]^{m / n} d x .
$$

where $A_{0}$ is a reference drainage area $\left(\mathrm{L}^{2}\right)$ (Perron and Royden, 2013).

Under steady-state conditions, Equation 2 implies that two proximal points across a divide, which reside at the same elevation $z$, should have the same $\chi$ value, providing that they evolved under the same spatial and temporal patterns of uplift $U$ and erodibility $K$ (Willett et al., 2014). On the contrary, differences in $\chi$ across a divide may be interpreted as a transient state (Willett et al., 2014; Mudd, 2016; Whipple et al., 2016; Forte and Whipple, 2018). A potential pathway to promote stability is then for the water divide to migrate toward the channel head with the higher $\chi$ value (Willett et al., 2014; Mudd, 2016). However, the relatively long timescale of landscape reorganization by the process of divide migration (Hasbargen and Paola, 2000; 
Goren et al., 2014; Reinhardt and Ellis, 2015; Whipple et al., 2016) makes this prediction challenging to test in natural field settings. The capability of $\chi$ maps (whereby $\chi$ is mapped along the drainage network) to yield reliable predictions of the occurrence and sense of landscape reorganization still needs to be investigated.

To demonstrate how tectonic horizontal deformation can alter the $\chi$ pattern of a drainage network, let us consider an idealized situation of two adjacent basins within a domain undergoing distributed right lateral shear, and with uniform climatic conditions and erodibility (Fig. 1). The imposed deformation causes both the geometry of the basins and the flow length to change (Fig. 1), leading to a drainage area distribution that no longer respects Equation 1. In our schematic model, the flow length along the fluvial system between the outlet and point A becomes greater than the flow length from the outlet to point B. The deformation of the drainage network can also induce variations in upstream drainage area (Goren et al., 2015). As a result of these two processes, the $\chi$ value becomes higher at point A with respect to point B (Eq. 3). In this configuration, $\chi$ values are higher on one side of the divide separating adjacent basins compare to the other side (Fig. 1), as documented for instance along the western flank of Mount Lebanon (Goren et al., 2015). The divide between points $\mathrm{A}$ and $\mathrm{B}$ is affected by a gradient in $\chi(\Delta \chi)$ and it is thus in an unstable configuration, hereafter named "stressed divide". As horizontal shear can induce $\Delta \chi \neq 0$ across divides, we hypothesize that these gradients can be used to infer the existence and sense of distributed horizontal deformation. The distribution of $\chi$ over a drainage network could thus be considered as a marker of horizontal deformation and it could contribute to a better constraining of horizontal deformation in areas affected by distributive strain (Hallet and Molnar, 2001; Ramsey et al., 2007; Castelltort et al., 2012; Goren et al., 2015; Yang et al., 2015; Guerit et al., 2016; Gray et al., 2017).

Consider next a landscape in which the drainage network is affected by $\Delta \chi$ across divides, as shown on Figure 1. In such a configuration, one possible path towards equilibrium is for the divides to migrate towards the channel head with the high $\chi$ value. Such reorganization will straighten the drainage basins with respect to their tectonically induced obliquity. $\chi$ maps can therefore be viewed as having a dual role. First, they may represent the state of landscape stress due to external tectonic horizontal forcing. Second, they may indicate the sense that landscape evolution might take in order to relax the stress (Willett et al., 2014; Forte and Whipple, 2018). As there is no time dependency in the parameter $\chi$ (Eq. 3), divides affected by a gradient in $\chi$ might reorganize at any time, i.e., soon or long after the emergence of the $\Delta \chi$, but they might also maintain this stressed configuration for an indefinite period, in particular when the forcing that stresses the landscape is persistant.

Here, our objective is twofold. First, we test whether a $\chi$ pattern can emerge due to tectonic horizontal deformation and can thus be used as a marker of such deformation. Second, we investigate whether $\chi$ gradients across water divides can be interpreted to anticipate the sense of divide migration and overall 
trajectories of network reorganization. We pursue these objectives by performing controlled analog experiments of relief growth under oblique convergence coupled with erosion and sedimentation. We discuss the processes by which reorganization occurs in the experiments, and we then analyze the relationships between the horizontal component of the orientation of $\chi$ gradients across divides, the imposed tectonic deformation, and the evolution of water divides.

\section{Methodology}

\section{Experimental setting}

To study the $\chi$ distribution and the evolution through time of drainage basins affected by lateral shear, we use the rainfall erosion and tectonic facility of Géosciences Montpellier Lab (France) designed to simulate the evolution of a landscape with controlled lithology, tectonic forcing and precipitation rates. The experimental apparatus has initially been developed to study the deformation of river network in oblique convergence setup, with a particular focus on the south island of New Zealand (Guerit et al., 2016). This specific context potentially favors the emergence of a drainage network affected by multiple gradients in $\chi$ across divides (Fig. 1), and we therefore took advantage of this unique facility to document the relationship between tectonic deformation, the $\chi$ pattern and fluvial network reorganization. Here, we analyze two replicate experiments performed with similar precipitation and shortening rates. This experimental approach allows direct observations of the drainage network evolution in response to known tectonic forcing, precipitation pattern and lithology, a situation that is rarely, if ever, met in natural systems (e.g., Whipple et al., 2016).

To induce distributed deformation across the relief and to simultaneously model fluvial processes, we use two layers of different granular mixtures. The lower layer simulating the middle crust is composed of $34 \%$ in weight of glass beads, $22 \%$ of talcum, $18 \%$ of PVC, and $1 \%$ of kaolinite mixed with $25 \%$ of water. It has a brittle-viscous behavior but its low cohesion $(280 \pm 50 \mathrm{~Pa})$ and coefficient of internal friction $(0.5 \pm 0.1)$ favor the propagation of the deformation over long distances (Guerit et al., 2016). This materiel never reaches the analyzed surface during the experiments. The material of the upper layer is made up of $37 \%$ in weight of glass beads, $24 \%$ of silica powder, $19 \%$ of PVC and $20 \%$ of water, and has higher cohesion and coefficient of internal friction $(750 \pm 50 \mathrm{~Pa}$ and $1.1 \pm 0.1$, respectively). This second material is designed to simulate the deformation of upper crustal rocks, surface erosion, sediment transport and deposition (Graveleau et al., 2011; Strak et al., 2011; Graveleau et al., 2015; Viaplana-Muzas et al., 2015). The properties of the upper layer allow simulating fluvial features such as drainage basins, fluvial network, terraces and alluvial fans. It is particularly well suited to model the evolution of accretionary wedges or deformed piedmonts (Graveleau 
et al., 2011, 2015). In association with the lower material, it can be used to simulate the evolution of a larger range (Guerit et al., 2016). We thus propose that our experiments are typical of tectonically active landscapes large enough for a mature drainage network to develop on their surface.

The two-layer material is loaded on a Mylar sheet resting on a $1.5 \times 2.5 \mathrm{~m}$ table and dragged with a convergence angle of $30^{\circ}$ toward a rigid backstop of $6 \mathrm{~cm}$ in height and with a $60^{\circ}$ dip, at a rate of $7.5 \mathrm{~cm} / \mathrm{h}$ (Fig. 2a). In the following, orientation is given with respect to the strike of this backstop viewed from above (Fig. 2a). The backstop creates a mechanical and a velocity discontinuity promoting the formation of an asymmetric doubly-vergent wedge (Fig. 2b), which grows mainly in-sequence by the progressive propagation of frontal thrusts and continuous out-of-sequence reactivation of former thrusts (Fig. 3a-c, Guerit et al., 2016). The experiment is stopped after $\sim 80 \mathrm{~cm}$ of shortening.

We use laser interferometry to acquire high-resolution DEMs of the surface every $5 \mathrm{~cm}$ of shortening (Figs. 2a and 3d-f). The frequency of DEM acquisition is chosen to maximize the number of acquisition during one experiment, given the shortening rate $(7.5 \mathrm{~cm} / \mathrm{h}$ ), the available laboratory time (4 days per run) and the time needed to dry the surface before DEM acquisition $(\sim 45 \mathrm{~min})$. For each experiment, a total number of 15 DEMs documents the evolution of the model, from the initial flat surface to the evolution of the wedge and drainage network. In addition, the evolution of the model surface is recorded by a 21 Mpx Canon 5D mark II camera placed above the table (Fig. 2a) and taking pictures every 30 seconds. The camera covers a field of view of $130 \mathrm{~cm} \times 70 \mathrm{~cm}$ with a resolution of $0.27 \mathrm{~mm} /$ pixel. We then use ENVI and GMT to perform sub-pixel image correlation to determine the incremental horizontal velocity field between two pictures over the wedge surface. In the undeformed areas, the horizontal velocity field is consistent with the imposed tectonic convergence angle and velocity. The velocity abruptly changes after crossing the main frontal thrust. From the topographic front to the main retro-fault, the velocity decreases in amplitude and gradually becomes aligned with the velocity discontinuity imposed by the backstop at depth (Fig. 3g-i).

The rock uplift rate can not be measured directly during the experiment because of the concomitant uplift and erosive processes. However, the morphology and the elevation of the wedge shows no major lateral variation (Fig. S1a) suggesting that the uplift rate can be approximated as a one dimensional function of distance from the backstop. This is consistent with the internal structure of the wedge that shows only slight lateral variation (Guerit et al., 2016). Based on the final topography, we can propose an average surface uplift rate of $0.6 \mathrm{~cm} / \mathrm{h}$ close to the main divide that decreases toward zero near the frontal thrust (Fig. S1c).

Sprinklers located above the setup generate rainfall with a spatial gradient decreasing from $50 \mathrm{~mm} / \mathrm{h}$ above the backstop to a few $\mathrm{mm} / \mathrm{h}$ at the pro-edge of the experimental table (Fig. $2 \mathrm{~b}$ ). The rainfall pattern is measured at the beginning of the experiments by the mean of small pots regularly spaced on the experimental table and submitted to precipitation for 20 minutes. Precipitations rates are then extrapolated over the whole 
experimental surface and this pattern is accounted for in the $\chi$ calculations (see Section Generation and analyses of the $\chi$ maps). The precipitation induces water runoff on the model and causes the development of a drainage network (Fig. 3a-c). On the retro-side, gravitational collapses are frequently observed. They alter the transport processes (e.g., Booth et al., 2013) and consequently the $\chi$ relationships. On the prowedge, the lower slope inhibits such collapses and therefore, in the following, we focus on the pro-side of the experimental wedge.

\section{General characteristics of the experimental drainage networks}

We extract the drainage networks and basins from each DEM using the Matlab TopoToolbox subroutines (Schwanghart and Kuhn, 2010). First, we create a matrix of flow direction based on the steepest slope between one cell and its neighbors. Then, we weight each cell of the flow direction grid by the precipitation rates by introducing $A^{\prime}=A \times P$ (e.g., Schwanghart and Kuhn, 2010; Chen et al., 2014; Murphy et al., 2016), and built the flow accumulation matrix. Finally, we extract the drainage network considering a flow accumulation threshold of 5000 pixels and imposing the outlets' location at the front of the pro-wedge.

During a run, a fluvial network develops on the topography, activating erosion and deposition over the whole landscape. During the experiments, the drainage basins respond to the imposed deformation by a clockwise rotation through time (see Guerit et al., 2016). However, the fluvial dynamics interacts with this imposed deformation and the observed morphology results from the competition between passive deformation and basin reorganization (Fig. 4). In order to analyze the dynamics of the drainage network, we consider two types of drainage basins: basins that extend from the main divide to the front of the wedge are denoted as large basins, while those that do not extend up to the main divide are labelled as small basins (Fig. 4).

The similarity of experimental landscapes with natural morphologies has often led to their use as analogs for natural landscapes (Schumm and Khan, 1972; Flint, 1973; Schumm et al., 1987; Hancock and Willgoose, 2003; Lague et al., 2003; Niemann and Hasbargen, 2005; Bonnet and Crave, 2006; Malverti et al., 2008; Paola et al., 2009; Graveleau et al., 2015; Viaplana-Muzas et al., 2015). In our experiments, this similarity is supported by several geomorphological parameters. First, the convergence angles of our drainage basins, which describe how efficiently the river paths converge toward the outlet within a drainage basin (Castelltort et al., 2009), are close to $10^{\circ}$, as observed for their natural counterparts (Castelltort et al., 2009; Jung et al., 2011; Castelltort and Yamato, 2013). Second, the average spacing ratio of the outlets along the relief front (width of the basins / distance from the front to the main orogen divide) is $\sim 2$, as documented in natural systems (Hovius, 1996; Talling et al., 1997; Castelltort and Simpson, 2006b). Finally, the power-law relationship derived between the length of the streams and their drainage areas (Hack's law) has a coefficient 
of 2.2 and an exponent of 0.53 , similar to values derived from natural settings (Hack, 1957; Montgomery and Dietrich, 1992; Lague et al., 2003; Walcott and Summerfield, 2009).

In addition, we observe a power-law relationship between the slope of the experimental streams and their drainage areas, and for both experiments, the best fit is obtained for a $m / n$ ratio of 0.2 (Fig. 5), in good agreement with the value derived from $\chi$-z plots after Perron and Royden, 2013 (Fig. S2). In natural settings, this ratio has been suggested to span a range of 0.35-0.70 (Whipple and Tucker, 1999; Kirby and Whipple, 2001; Brocklehurst and Whipple, 2002; Wobus et al., 2006; McNamara et al., 2006), although lower values can be observed in the field (Vanacker et al., 2015) and in experimental landscapes (Lague et al., 2003). A low value of this index can be attributed to systems affected by mass flow transport rather than purely fluvial transport of the sediments (Stock and Dietrich, 2003; Lague et al., 2003; Niemann and Hasbargen, 2005; Booth et al., 2013; Singh et al., 2015). It could also be related to the emergence of the thrusts at the front of the wedge during the experiments that perturbs the fluvial system (Vanacker et al., 2015). On Figure 5, a break in slope is observed for drainage areas larger than $10^{4} \mathrm{~cm}^{2}$. Basins with a large drainage area could thus have a higher concavity of $\sim 0.5$. The $m / n$ ratio is required to built the $\chi$ maps (Eq. 3 ) and it is possible to generate such maps using different $m / n$ values according to the size of the drainage area. However, we observed that introducing such complexity does not affect the locations and orientations of the $\Delta \chi$. Accordingly, for simplicity, we consider a single, representative value of $m / n=0.2$ along the whole drainage network, and this power-law relationship allows us to derive $\chi$ (Eqs. 1-3) along the stream network, even for small basins (Hergarten et al., 2016).

We use the analog landscapes, first, to discuss the evolution of the drainage network, and second, to analyse the relation between $\chi$ patterns, tectonic deformation and network reorganization. Excluding the initial stages of relief and drainage development, we obtained a total number of 15 DEMs from the two replicate experiments, for which we applied the procedure described in the following section.

\section{Generation and analyses of the $\chi$ maps}

Variations in erodibility can be accounted for by considering $K$ as a function of $x$ in Equation 2 (Perron and Royden, 2013; Willett et al., 2014) but in our experiments, only the surface material is affected by erosion. We can thus consider that the erodibility, $K$, is uniform. As discussed above, the uplift $U$ varies perpendicularly to the backstop, and since it is the dominant direction of the drainage network, the uplift pattern is not expected to affect the $\chi$ pattern. At the outlets of the drainage basins, the elevation $z$ is equal to 0 and is taken as the reference elevation for the $\chi$ calculation (i.e., $z\left(x_{b}\right)$, Eq. 2). As discussed in the previous section, we use an $m / n$ ratio of 0.2 and we consider a reference drainage area $A_{0}$ of 1 pixel to calculate $\chi$ on each pixel of the drainage network (Eq. 3). Then, we map all the pairs formed by two channel 
heads, or by a channel head and a channel, sharing a common divide with different values of $\chi$ on each side. The pairs are mapped according to the following rules :

1. Gradients of $\chi$ are identified and mapped by eyes, based on the difference in color on each side of a divide.

2. Most pairs are made of two channel heads across a divide as defined in Willett et al. (2014) (Fig. S4a-b). We also pair a channel head with a channel if the low $\chi$ is on the channel head (Fig. S4c). Finally, we pair high $\chi$ channel head with low $\chi$ channel if the considered channel is extremely close to divide (Fig. S4d-e).

3. A single channel head cannot contribute to more than a single pair. If several pairs are possible, we select the closest channel heads or channels (Fig. S4f).

4. We favor left-right pairs (parallel to the backstop and perpendicular to the dominant flow direction) rather than the up-down pairs as the imposed deformation is expected to induce divide migration along a left-right trend (Fig. S4f).

Mapping by hand has proved to be the more efficient way to identify the pairs and the maps were checked independently by several persons to avoid individual bias. A typical $\chi$ map is presented on Figure 6. For each pair, the orientation of the $\chi$ gradient is indicated: ellipses and rectangles denote gradients where the higher $\chi$ is to the left and right side of the divide, respectively. As we account for the rainfall variation in space, we insure that the potential $\chi$ gradients are not related to the precipitation pattern (Perron and Royden, 2013; Whipple et al., 2016; Forte and Whipple, 2018). These maps are thus used to relate the imposed tectonic deformation to the state of stress of the fluvial drainage network.

In addition, to investigate the capacity of $\chi$ to accurately highlight divides prone to migration and the sense of reorganization, we analyze pairs of consecutive DEMs. Whipple et al. (2016) proposed that it might be difficult to notice migrating, or potentially migrating, divides from $\chi$ maps when divide migration is parallel to the main topography, but they noted that $\chi$ is likely to record divide migrations that occurred perpendicularly to the main topography, or that occurred recently, whatever the direction of the migration (Willett et al., 2014; Whipple et al., 2016). These two latter situations are met in our experiments as we look at migrations between adjacent basins located on the same side of the wedge and at frequent time intervals. Each pair of DEMs is considered as an independent data set. Accordingly, the first DEM of the pair is defined as the initial landscape at time $T_{0}$ while the second DEM is defined as the final landscape at time $T_{1}$, and for each pair of DEMs, we log the evolution of the stressed divides between the initial $\left(T_{0}\right)$ and final $\left(T_{1}\right)$ landscapes. Three outcomes are possible: 1$)$ the divide does not evolve between $T_{0}$ and $\left.T_{1}, 2\right)$ the divide migrates toward the high $\chi$ or 3 ) the divide migrates toward the low $\chi$. It is important to note that $\chi$ differences across divides indicate the potential instability of the basins that bound them and may 
provide a prediction for a sense of divide migration that can relax the instability and promote equilibrium. However, the timescale over which migration and reorganization take place cannot be extracted from the $\chi$ analysis. A divide which has not migrated between $T_{0}$ and $T_{1}$ will be thus labelled as not evolving, but it might migrate in the following time step. Due to the time lag between consecutive DEMs, it is not always possible to identify the same basin on both DEMs, and we restrict this analysis to gradients located along basins that were reliably recognized across two successive DEMs. This leads us to 12 pairs of successive experimental landscapes.

To avoid bias related to a limited number of observations, this study is based on the analysis of 15 different DEMs and 12 pairs of DEMs, that correspond to different states of maturity of both the relief and the drainage network (Fig. 3). Our data set thus covers a large variety of landscapes, from a thin wedge drained by multiple basins to a thicker and wider one drained by fewer basins. The frequency at which the DEMs are acquired (one every $5 \mathrm{~cm}$ of shortening) is set by the experimental constraints and does not allow a continuous record of the drainage evolution. This induces a potential bias in the observations as we are not able to document all the basin reorganization events, but the dynamics of reorganization of the stream network and its relationship with $\chi$ distribution in the drainage network is not related to the frequency at which we observe the landscape. We thus propose that our observations are representative in a statistical sense of the behavior of a drainage network submitted to distributed horizontal strain. In the following, we first describe the evolution of the drainage network and then, we present and discuss the main results of this study.

\section{Results}

\section{Evolution of the drainage network}

The drainage network develops early in the experiment and evolves from numerous, small and poorly ramified streams (Fig. 3a) to a mature system of well-developed basins with dendritic stream networks (Fig. 3c). During the experiment, the number of basins draining to the front of the relief decreases (Fig. S3) while they maintain an average spacing ratio by their progressive coalescence into bigger basins as the relief grows outward (Castelltort and Simpson, 2006a,b; Graveleau, 2008). Fluvial valleys are quite wide and this could be related to the erosive nature of the surface material which favors lateral erosion. Although we do not observe evidence for landslides on the pro-side, lateral erosion could also be enhanced by small but continuous collapses along the flanks of the fluvial valleys, that could deliver easily transportable material to the rivers (Booth et al., 2013).

Reorganization is related to several processes of stream captures between adjacent basins. Small streams 
generally initiate along the scarps exposed when a new thrust reaches the surface (Fig. 3). These streams often evolve by regressive erosion and eventually connect with the pre-existing drainage network, leading to a major drainage reorganization by capturing upslope reaches (Fig. 7a-d). Large basins mainly evolve in response to two different processes. First, drainage shifts and rerouting of catchments into neighboring basins often arise from areas of sediment deposition where flow divergence and lateral migration are enhanced (Fig. 7e-h). Such locations correspond to alluvial fans initially formed in the alluvial plain (outside of the uplifting wedge) that were later incorporated to the relief. Second, when a new thrust emerges at the front of the wedge, the outlets migrate toward the front and this displacement induces major reorganization, in particular of the large basins. Although the location of the outlets is controlled by the main thrust, and thus, by the tectonic forcing, we observe that the river path is not very sensitive to the presence of the folds that precede faulting. In fact, the drainage network is mostly transverse to the fold axis and rivers show almost no deviation of their paths related to the presence of folds or faults (Fig. 4). The capacity of rivers to cut through these topographic structures could be related from the high precipitation and limited uplift rate which enhance lateral erosion rather vertical incision (Bufe et al., 2016).

Drainage reorganization also originates from the river headwaters, which are sensitive to sudden erosive events such as landslides, even with limited involved volumes. In fact, small topographic evolutions occurring in the headwaters of a drainage basins can induce reorganization of the whole network downstream by modifying the position of the divide between two adjacent basins (e.g., Bishop, 1995).

The very dynamic behavior of our experimental landscape might be related to the mechanical properties of our experimental material, designed to model fluvial processes such as channelization, avulsion or channel migrations (Graveleau et al., 2011; Guerit et al., 2016). Processes of reorganization are enhanced by lateral migration of channels in our non-consolidated experimental material (Bishop, 1995; Pelletier, 2003), when a more cohesive material would have eroded in the shape of incised valleys where lateral migration is limited (badland type morphology) (e.g., Bonnet and Crave, 2006).

Overall, we observe that the experimental drainage networks exhibit geometrical properties that are similar to natural networks, and that they evolve by processes of capture by headward stream erosion, downstream coalescence of streams, and avulsion in intramontane distributive alluvial systems. The analogy of geometric properties and of the fluvial processes we identify with those inferred in natural case studies suggests that the conclusions drawn from the experiments on the relationship between $\chi$, the imposed tectonic deformation and the evolution of the drainage network may also apply to natural settings. 


\section{Horizontal tectonic strain revealed by $\chi$ maps}

The horizontal component of the velocity field induces a rotation of the drainage basins during the experiments. However, the fluvial dynamics compete with the imposed deformation and the amount of total rotation is then limited. For example, the average orientation of the basins shown on Figure 4 is $7^{\circ}$ when the expected rotation for a purely passive marker should be $20^{\circ}$ (Guerit et al., 2016). Therefore, the morphology of the drainage system in the experiments cannot be considered as a fully reliable marker of horizontal shear (Guerit et al., 2016), illustrating the need for other markers of horizontal strain.

The analysis of the 15 experimental $\chi$ maps reveals that the $\chi$ pattern along the drainage network is on average consistent with the imposed deformation: among the 719 mapped divides affected by a $\chi$ gradient, $67 \%$ exhibit higher $\chi$ on their left side than on their right side (Fig. 8a, Tab. S1), in good agreement with the pattern expected from the imposed deformation (Fig. 1). However, the large and the small basins show a different $\chi$ pattern. $70 \%$ of the $\chi$ gradients affecting divides along large basins have a higher $\chi$ on their left side. This proportion is only $58 \%$ for the small basins, that thus exhibit a more symmetrical $\chi$ pattern along their divides (Tab. S1). This suggests that in many cases the divides that delineate the small basins show a tendency to either move away from each other allowing the basin to grow, or to move towards each other and causing the basin to shrink. This might be related to the size of these basins, which experience less horizontal deformation than the large ones because of their limited extension.

It is noticeable that the distribution of $\chi$ values does not evolve significantly during the experiments (Fig. S5) despite the frequent reorganizations and the fact that the number of stressed divides on which the analyses is based changes from one DEM to another (Fig. 8a). This implies that the topologic stress released by reorganizations is continuously balanced by new stress added by the ongoing tectonic deformation, resulting in a morphometric dynamic steady-state.

It thus appears that the $\chi$ distribution, especially across the divides of the large basins, reflects the imposed large-scale tectonic strain and that systematic pattern in $\chi$ between adjacent drainage basins can be used to assess horizontal deformation.

\section{Basin evolution and imposed horizontal deformation}

Next, we study the evolution of the stressed divides between $T_{0}$ and $T_{1}$. From the 12 pairs of DEMs, we identified $317 \Delta \chi$ along the divides of the large basins, among which $27 \%$ did not evolve between $T_{0}$ and $T_{1}$. Focusing on the ones that did evolve, we observe that $66 \%$ of the divides affected by a gradient migrated in agreement with $\Delta \chi$, i.e., migrated toward the high $\chi$ (Fig. 9, Tab. S2). Along the small basins, we analyzed $63 \Delta \chi$. Only $16 \%$ of the gradients did not evolve between $T_{0}$ and $T_{1}$, suggesting that the small basins are more prone for reorganization than the large ones. Among the divides that did evolve, $62 \%$ of the migrations 
occurred toward the high $\chi$ (Fig. 9, Tab. S2). Considering all the gradients together, the direction of the observed migrations is correctly anticipated by the $\chi$ pattern at $T_{0}$ for $65 \%$ of the stressed divides (Fig. 8b, Tab. S2).

Finally, we notice that the direction of divide migration, beyond the relation with the $\Delta \chi$ orientation, is quite different between the large and the small basins (Fig. 8c). In fact, migration of the divides that delineate large basins mostly occurred toward the left (64\%), suggesting that these basins reorganize in response to the imposed horizontal deformation (Tab. S3). For the small basins, we observe that $42 \%$ of migrations toward the left (Tab. S3). This is consistent with the more symmetrical $\Delta \chi$ pattern along these basins (Tab. S1), and suggests that the small basins primary evolve in order to grow or to shrink, rather than in response to the imposed deformation.

\section{Discussion}

\section{Imposed tectonic strain and $\chi$ pattern}

The experiments presented here demonstrate that, on average, the orientation of the $\Delta \chi$ is consistent with the pattern expected from the imposed tectonic horizontal deformation, as observed for example along Mount Lebanon (Goren et al., 2015). However, we also observe divides affected by $\Delta \chi$ with the high $\chi$ on the right side of the divide, i.e., reversed with respect to our expectations based on the imposed deformation (Figs. 1 and 8a, Tab. S1). Small basins are statistically more affected by gradients with the high $\chi$ on the right side of the divide, but large basins also have a non-negligible fraction of gradients inconsistent with the imposed deformation. Such situations, where a high $\chi$ is observed on the right side of the stressed divide, could be related to transient stages following for example a stream capture or the migration of an outlet. In such scenario, streams might need some time to adapt to the new geometry and $\Delta \chi$ could be disconnected from the imposed deformation. In addition, the wedge on which the drainage network develops is constantly growing, with the regular emergence of new thrusts at its front. These major tectonic disruptions, with predominantly vertical gradients in uplift, provoke massive reorganizations of the drainage network in response to the outlet migration toward the relief front. These sudden events affect the river path and could induce $\chi$ gradients which are not necessarily consistent with the average imposed horizontal deformation. Consequently, we expect these "reversed" gradients to be less frequent for a wedge with a constant width, but the design of the experimental setup did not allow us to explore this aspect. Yet, even with our experimental limitations, the $\chi$ maps derived from our experiments reflect the imposed horizontal deformation, with a recurrent $\Delta \chi$ pattern between adjacent basins (Figs. 1, 6, 8a). This suggests that $\chi$ pattern can be used as an indicator of the presence of horizontal distributed strain. 
The exact results of this study ( $\sim 2 / 3$ of the $\Delta \chi$ oriented as expected from the imposed deformation) are related to our experimental setup and material and can not be directly extended to natural cases. In addition, we used a material that is easily eroded and that favors lateral erosion. In return, our channels deviate from purely bedrock channels for which the $\chi$ metric has been initially proposed, and we thus expect $\chi$ to better mimic the imposed deformation in pure bedrock drainage network.

\section{Drainage evolution and sense of $\Delta \chi$}

Our analysis reveals that divide migrations occurred mostly in agreement with the direction of $\Delta \chi$. However, we also observe in some cases migrations toward the low $\chi$ (Fig. 8, Tab. S2) and migrations in the absence of any gradient (Fig. S6). Such behavior can be related to several processes that affect both the small and the large basins, as shown by the similar proportion of migrations toward the low $\chi$ value in both cases ( $38 \%$ and $34 \%$, respectively, Tab. S2).

First, when a new thrust reaches the surface, the whole drainage must adjust. As discussed previously, small streams emerge at the front of the relief and they tend to erode backward and connect to the main drainage network. Such a process can trigger widespread reorganization but it is not anticipated by $\chi$ maps. In addition, when a thrust emerges, outlets move toward the new front and this event favors also major reorganizations, such as basin capture or merging, which have no signature in the DEM that was taken before the emergence of the fault. These short but dramatic events are not foreseen in the $\chi$ maps at $T_{0}$. The tectonic disruptions might also be responsible for the observed migrations toward the right along the large basins.

Second, areas dominated by deposition are prone to stream avulsion (Fig. 7), and changes in the river path induced by such processes can modify the stream network, a process that, again, can not be foreseen from the $\chi$ distribution at $T_{0}$. In pure bedrock channels, this process should not occur and we therefore expect less migrations toward the low $\chi$ in such context.

Third, migrations that occurred in places where the difference in $\chi$ would not predict one, are often observed in close proximity to areas that reorganized according to the $\Delta \chi$ predictions. These unanticipated reorganizations could be the outcome of proximal reorganizations through a feedback by which one reorganization induces a nearby reorganization (Fig. 7).

The processes discussed above (localized faulting, along valley deposition and avulsion, and nearby reorganization) are not mutually exclusive and they might interact together to induce changes in basin geometry and divide migrations, which can equally be toward high $\chi$, toward low $\chi$ or along divides that appeared in equilibrium according to their $\chi$ pattern at $T_{0}$. To summarize, it is likely that migrations that are not anticipated in $\chi$ maps are related to the perturbations of the topography associated with the brittle 
tectonic deformation of the experimental wedge and to the rapid (i.e., with a frequency higher than the frequency of DEM acquisition) evolution of the fluvial network, including avulsion.

Deviations from the expected evolution could also reveal limitations of the $\chi$ approach itself. In fact, the current analysis and the $\chi$ approach assume a power law relation between the slope and the drainage area. Other processes that may control the stability of the drainage network such as dynamic width variations or variable sediment flux are not accounted for in the $\chi$ analysis and may also influence the tendency of the drainage network to reorganize.

\section{Conclusions}

Our analysis of experimental fluvial landscapes developed in a rainfall-sandbox wedge growing in an oblique collision setting allows testing the capability of the $\chi$ metric to reveal tectonic horizontal shear deformation and to indicate the sense of drainage reorganization for a landscape submitted to horizontal shear. The experiments show that the spatial distribution of $\chi$ along a river network is consistent with the imposed deformation field, where $\sim 2 / 3$ of the mapped gradients have a higher $\chi$ on the left side of the divide for right lateral shear. This suggests that $\chi$ maps can be used to infer regional tectonic strain in natural settings. In addition, when a divide affected by a $\Delta \chi$ migrates, our analysis demonstrates that the orientation of $\chi$ gradients statistically anticipate $\sim 2 / 3$ of the sense of divide migrations in our experimental landscape. We propose that reorganizations that are not correctly predicted by the $\chi$ pattern are associated with fluvial avulsion and topographic disruptions related to tectonic structures. Overall, this study supports the view that $\chi$ is a statistically reliable predictor of drainage evolution. Indeed, we used a specific setup with highly dynamic drainage basins and our fluvial network deviates from a pure bedrock network. Yet, the gradients in $\chi$ do hint at instable divides in our experimental channels and we thus expect $\chi$ to be a better indicator of instable divides in pure bedrock rivers.

\section{Acknowledgements}

We are thankful to Simon Mudd, an anonymous reviewer and the associated editor for their comments that strongly improved the quality of the paper. We thanks C. Romano for his strong support for the design of the setup and during the experiments, M. Henriquet for his experimental assistance during the first phase of this work and T. Kaner for his help in $\chi$ maps analysis. This work was supported by the Swiss National Science Foundation project "Earth Surface Signaling System" (grant No 200021-146822) to S. Castelltort. 


\section{Références}

Bishop, P.: Drainage rearrangement by river capture, beheading and diversion, Progress in Physical Geography, 19, 449-473, 1995.

Bishop, P.: Long-term landscape evolution: linking tectonics and surface processes, Earth Surface Processes and Landforms, 32, 329-365, 2007.

Bonnet, S. and Crave, A.: Macroscale dynamics of experimental landscapes, Geological Society, London, Special Publications, 253, 327-339, 2006.

Booth, A. M., Roering, J. J., and Rempel, A. W.: Topographic signatures and a general transport law for deep-seated landslides in a landscape evolution model, Journal of Geophysical Research: Earth Surface, 118, 603-624, 2013.

Brocard, G., Teyssier, C., Dunlap, W., Authemayou, C., Simon-Labric, T., Cacao-Chiquín, E., GutiérrezOrrego, A., and Morán-Ical, S.: Reorganization of a deeply incised drainage: role of deformation, sedimentation and groundwater flow, Basin Research, 23, 631-651, 2011.

Brocklehurst, S. and Whipple, K.: Glacial erosion and relief production in the Eastern Sierra Nevada, California, Geomorphology, 42, 1-24, 2002.

Brookfield, M.: The evolution of the great river systems of southern Asia during the Cenozoic India-Asia collision: rivers draining southwards, Geomorphology, 22, 285-312, 1998.

Bufe, A., Paola, C., and Burbank, D. W.: Fluvial bevelling of topography controlled by lateral channel mobility and uplift rate, Nature Geoscience, 2016.

Castelltort, S. and Simpson, G.: Growing mountain ranges and quenched river networks, Comptes Rendus Geoscience, 338, 1184-1193, 2006a.

Castelltort, S. and Simpson, G.: River spacing and drainage network growth in widening mountain ranges, Basin Research, 18, 267-276, 2006b.

Castelltort, S. and Yamato, P.: The influence of surface slope on the shape of river basins: Comparison between nature and numerical landscape simulations, Geomorphology, 192, 71-79, 2013.

Castelltort, S., Simpson, G., and Darrioulat, A.: Slope-control on the aspect ratio of river basins, Terra Nova, 21, 265-270, 2009. 
Castelltort, S., Goren, L., Willett, S., Champagnac, J.-D., Herman, F., and Braun, J.: River drainage patterns in the New Zealand Alps primarily controlled by plate tectonic strain, Nature Geoscience, 5, 744-748, 2012.

Chen, K., Gumiaux, C., Augier, R., Martelet, G., Chen, Y., and Wang, Q.: Integrated multidisciplinary approach to constrain range fronts structure, a case study of the northern Tianshan piedmont (NW China), Bulletin de la Société Géologique de France, 185, 379-392, 2014.

Clark, M., Schoenbohm, L., Royden, L., Whipple, K., Burchfiel, B., Zhang, X., Tang, W., Wang, E., and Chen, L.: Surface uplift, tectonics, and erosion of eastern Tibet from large-scale drainage patterns, Tectonics, 23, TC1006, 2004.

Flint, J.: Stream gradient as a function of order, magnitude, and discharge, Water Resources Research, 10, 969-973, 1974.

Flint, J.-J.: Experimental development of headward growth of channel networks, Geological Society of America Bulletin, 84, 1087-1094, 1973.

Forte, A. M. and Whipple, K. X.: Criteria and tools for determining drainage divide stability, Earth and Planetary Science Letters, 493, 102-117, 2018.

Goren, L., Willett, S., Herman, F., and Braun, J.: Coupled numerical-analytical approach to landscape evolution modeling, Earth Surface Processes and Landforms, 39, 522-545, 2014.

Goren, L., Castelltort, S., and Klinger, Y.: Modes and rates of horizontal deformation from rotated river basins: Application to the Dead Sea fault system in Lebanon, Geology, 43, 843-846, 2015.

Graveleau, F.: Interactions Tectonique, Erosion, Sédimentation dans les avant-pays de chaînes : Modélisation analogique et étude des piémonts de l'est du Tian Shan (Asie centrale), 487 p., Université Montpellier II Sciences et Techniques du Languedoc, France, 2008.

Graveleau, F., Hurtrez, J.-E., Dominguez, S., and Malavieille, J.: A new experimental material for modeling relief dynamics and interactions between tectonics and surface processes, Tectonophysics, 513, 68-87, 2011.

Graveleau, F., Strak, V., Dominguez, S., Malavieille, J., Chatton, M., Manighetti, I., and Petit, C.: Experimental modelling of tectonics-erosion-sedimentation interactions in compressional, extensional, and strike-slip settings, Geomorphology, 244, 146-168, 2015. 
Gray, H. J., Shobe, C. M., Hobley, D. E., Tucker, G. E., Duvall, A. R., Harbert, S. A., and Owen, L. A.: Offfault deformation rate along the southern San Andreas fault at Mecca Hills, southern California, inferred from landscape modeling of curved drainages, Geology, 2017.

Grosjean, A.-S., Pittet, B., Gardien, V., Leloup, P.-H., Mahéo, G., and Barraza Garcia, J.: Tectonic heritage in drainage pattern and dynamics: the case of the French South Alpine Foreland Basin (ca. 45-20 Ma), Basin Research, 2015.

Guerit, L., Dominguez, S., Malavieille, J., and Castelltort, S.: Deformation of an experimental drainage network in oblique collision, Tectonophysics Special Issue, 693, 2016.

Hack, J. T.: Studies of longitudinal stream profiles in Virginia and Maryland, Tech. rep., GSP, 1957.

Hallet, B. and Molnar, P.: Distorted drainage basins as markers of crustal strain east of the Himalaya, Journal of Geophysical Research: Solid Earth, 106, 13 697-13 709, 2001.

Hancock, G. and Willgoose, G.: A qualitative and quantitative evaluation of experimental model catchment evolution, Hydrological processes, 17, 2347-2363, 2003.

Hasbargen, L. E. and Paola, C.: Landscape instability in an experimental drainage basin, Geology, 28, 1067-1070, 2000.

Hergarten, S., Robl, J., and Stüwe, K.: Tectonic geomorphology at small catchment sizes-extensions of the stream-power approach and the $\chi$ method, Earth Surface Dynamics, 4, 1, 2016.

Hovius, N.: Regular spacing of drainage outlets from linear mountain belts, Basin Research, 8, 29-44, 1996.

Howard, A. D. and Kerby, G.: Channel changes in badlands, Geological Society of America Bulletin, 94, 739-752, 1983.

Jung, K., Niemann, J., and Huang, X.: Under what conditions do parallel river networks occur?, Geomorphology, 132, 260-271, 2011.

Kirby, E. and Whipple, K.: Quantifying differential rock-uplift rates via stream profile analysis, Geology, $29,415-418,2001$.

Kirby, E. and Whipple, K.: Expression of active tectonics in erosional landscapes, Journal of Structural Geology, 44, 54-75, 2012.

Lague, D.: The stream power river incision model: evidence, theory and beyond, Earth Surface Processes and Landforms, 39, 38-61, 2014. 
Lague, D., Crave, A., and Davy, P.: Laboratory experiments simulating the geomorphic response to tectonic uplift, Journal of Geophysical Research: Solid Earth, 108, 2003.

Lavé, J. and Avouac, J.: Fluvial incision and tectonic uplift across the Himalayas of central Nepal, Journal of Geophysical Research: Solid Earth, 106, 26 561-26 591, 2001.

Malverti, L., Lajeunesse, E., and Metivier, F.: Small is beautiful: Upscaling from microscale laminar to natural turbulent rivers, Journal of Geophysical Research - Earth Sciences, 113, doi:10.1029/2007JF000974, 2008.

McNamara, J., Ziegler, A., Wood, S., and Vogler, J.: Channel head locations with respect to geomorphologic thresholds derived from a digital elevation model: A case study in northern Thailand, Forest Ecology and Management, 224, 147-156, 2006.

Montgomery, D. and Dietrich, W.: Channel initiation and the problem of landscape scale, Science, 255, 826-830, 1992.

Mudd, S.: Detection of transience in eroding landscapes, Earth Surface Processes and Landforms, DOI: 10.1002/esp.3923, 2016.

Mudd, S. M., Attal, M., Milodowski, D. T., Grieve, S. W., and Valters, D. A.: A statistical framework to quantify spatial variation in channel gradients using the integral method of channel profile analysis, Journal of Geophysical Research: Earth Surface, 119, 138-152, 2014.

Murphy, B., Johnson, J., Gasparini, N., and Sklar, L.: Chemical weathering as a mechnism for the climatic control of bedrock river incision, Nature Letters, 532, $223-227,2016$.

Niemann, J. and Hasbargen, L.: A comparison of experimental and natural drainage basin morphology across a range of scales, Journal of Geophysical Research: Earth Surface, 110, doi:10.1029/2004JF000 204, 2005.

Paola, C., Straub, K., Mohrig, D., and Reinhardt, L.: The "unreasonable" effectiveness of stratigraphic and geomorphic experiments, Earth-Science Reviews, 97, 1-43, 2009.

Pelletier, J.: Drainage basin evolution in the Rainfall Erosion Facility: dependence on initial conditions, Geomorphology, 53, 183-196, 2003.

Perron, T. and Royden, L.: An integral approach to bedrock river profile analysis, Earth Surface Processes and Landforms, 38, 570-576, 2013. 
Pritchard, D., Roberts, G., White, N., and Richardson, C.: Uplift histories from river profiles, Geophysical research letters, 36, L24 301, 2009.

Ramsey, L., Walker, R., and Jackson, J.: Geomorphic constraints on the active tectonics of southern Taiwan, Geophysical Journal International, 170, 1357-1372, 2007.

Reinhardt, L. and Ellis, M. A.: The emergence of topographic steady state in a perpetually dynamic selforganized critical landscape, Water Resources Research, 51, 4986-5003, 2015.

Royden, L. and Perron, T.: Solutions of the stream power equation and application to the evolution of river longitudinal profiles, Journal of Geophysical Research: Earth Surface, 118, 497-518, 2013.

Schumm, S. and Khan, H.: Experimental study of channel patterns, Geological Society of America Bulletin, 83, 1755-1770, 1972.

Schumm, S., Mosley, M., and Weaver, W.: Experimental fluvial geomorphology, John Wiley and Sons Inc., New York, NY, 1987.

Schwanghart, W. and Kuhn, N.: TopoToolbox: A set of Matlab functions for topographic analysis, Environmental Modelling \& Software, 25, 770-781, 2010.

Singh, A., Reinhardt, L., and Foufoula-Georgiou, E.: Landscape reorganization under changing climatic forcing: Results from an experimental landscape, Water Resources Research, 51, 4320-4337, 2015.

Stock, J. and Dietrich, W. E.: Valley incision by debris flows: Evidence of a topographic signature, Water Resources Research, 39, 2003.

Strak, V., Dominguez, S., Petit, C., Meyer, B., and Loget, N.: Interaction between normal fault slip and erosion on relief evolution: Insights from experimental modelling, Tectonophysics, 513, 1-19, 2011.

Talling, P., Stewart, M., Stark, C., Gupta, S., and Vincent, S.: Regular spacing of drainage outlets from linear fault blocks, Basin Research, 9, 275-302, 1997.

Vanacker, V., von Blanckenburg, F., Govers, G., Molina, A., Campforts, B., and Kubik, P.: Transient river response, captured by channel steepness and its concavity, Geomorphology, 228, 234-243, 2015.

Viaplana-Muzas, M., Babault, J., Dominguez, S., Van Den Driessche, J., and Legrand, X.: Drainage network evolution and patterns of sedimentation in an experimental wedge, Tectonophysics, 664, 109-124, 2015.

Walcott, R. and Summerfield, M.: Universality and variability in basin outlet spacing: implications for the two-dimensional form of drainage basins, Basin Research, 21, 147-155, 2009. 
Whipple, K. and Tucker, G.: Dynamics of the stream-power river incision model: Implications for height limits of mountain ranges, landscape response timescales, and research needs, Journal of Geophysical Research: Solid Earth (1978-2012), 104, 17 661-17674, 1999.

Whipple, K., Forte, A., DiBiase, R., Gasparini, N., and Ouimet, W.: Timescales of landscape response to divide migration and drainage capture: Implications for the role of divide mobility in landscape evolution, Journal of Geophysical Research: Earth Surface, 2016.

Whittaker, A.: How do landscapes record tectonics and climate?, Lithosphere, 4, 160-164, 2012.

Willett, S., McCoy, S., Perron, T., Goren, L., and Chen, C.-Y.: Dynamic reorganization of river basins, Science, 343, $1248765,2014$.

Wobus, C., Whipple, K., Kirby, E., Snyder, N., Johnson, J., Spyropolou, K., Crosby, B., and Sheehan, D.: Tectonics from topography: Procedures, promise, and pitfalls, Geological Society of America Special Papers, 398, 55-74, 2006.

Yang, R., Willett, S. D., and Goren, L.: In situ low-relief landscape formation as a result of river network disruption, Nature, 520, 526-529, 2015. 


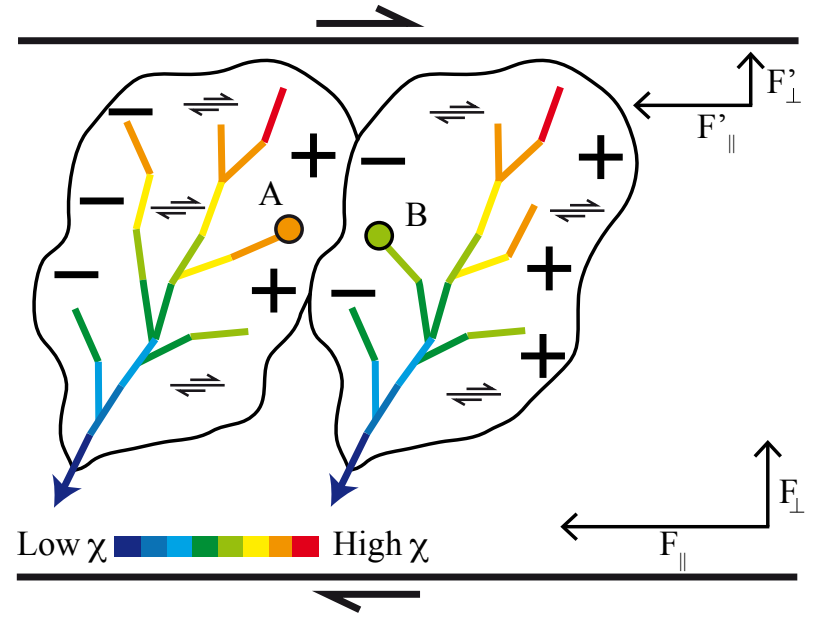

FigURE 1 - Schematic drainage network submitted to an oblique distributed strain bounded by two main faults (bold black line). The fault-parallel and fault-perpendicular components of the motion, $F_{\|}$and $F_{\perp}$ respectively, decrease toward the headwaters of the rivers. In response to this tectonic strain, the basins are rotated clockwise and exhibit higher $\chi$ values on their right side (+) than on their left side (-). The color dots indicate two points, $A$ and B, along the river path, located at the same elevation and at the same distance from the wedge front. As a consequence of the basin deformation, the river path between the outlet and $A$ is longer than the one between the outlet and B: the two points do not have the same $\chi$ value. Accordingly, the divide separating the two adjacent basins experiences a higher $\chi$ value on its left side than on its right side. This figure is available in color online at www.interscience.wiley.com/journal/espl.

(a)
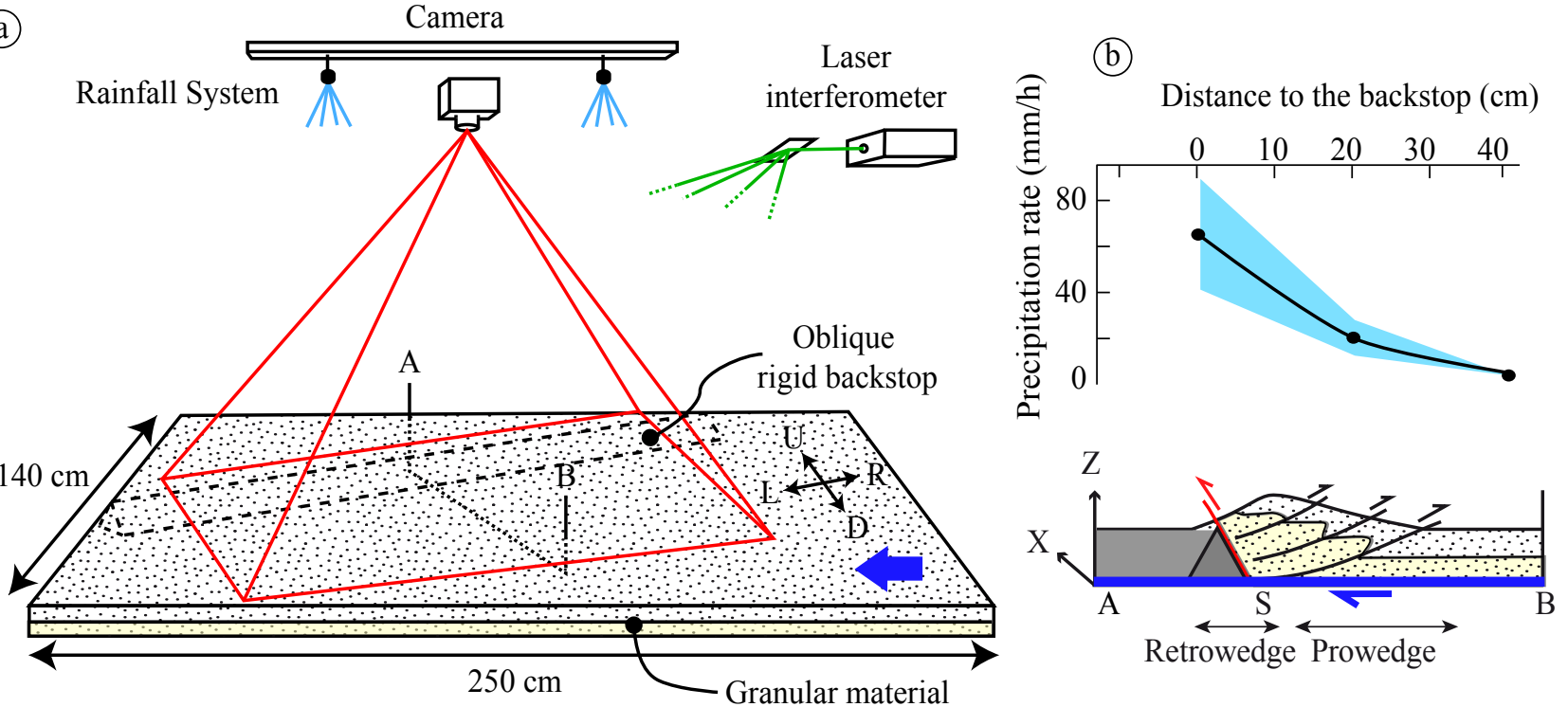

FIGURE 2 - a) Experimental setup composed by a table on which a rigid backstop is fixed. Erosion is induced by the rainfall system located above the table and the model evolution is recorded by pictures taken by the camera. At regular time steps, a laser interferometry system acquires a high-resolution DEM of the model. b) When the sediments loaded on the table are transported toward the backstop (blue arrow), a doubly-vergent, asymmetric wedge forms, with a short and steep retro-side, and a longer and less steep pro-side. The precipitation rate decreases along a cross-section perpendicular to the model orogen (A-B). This figure is available in color online at www.interscience.wiley.com/journal/espl. 

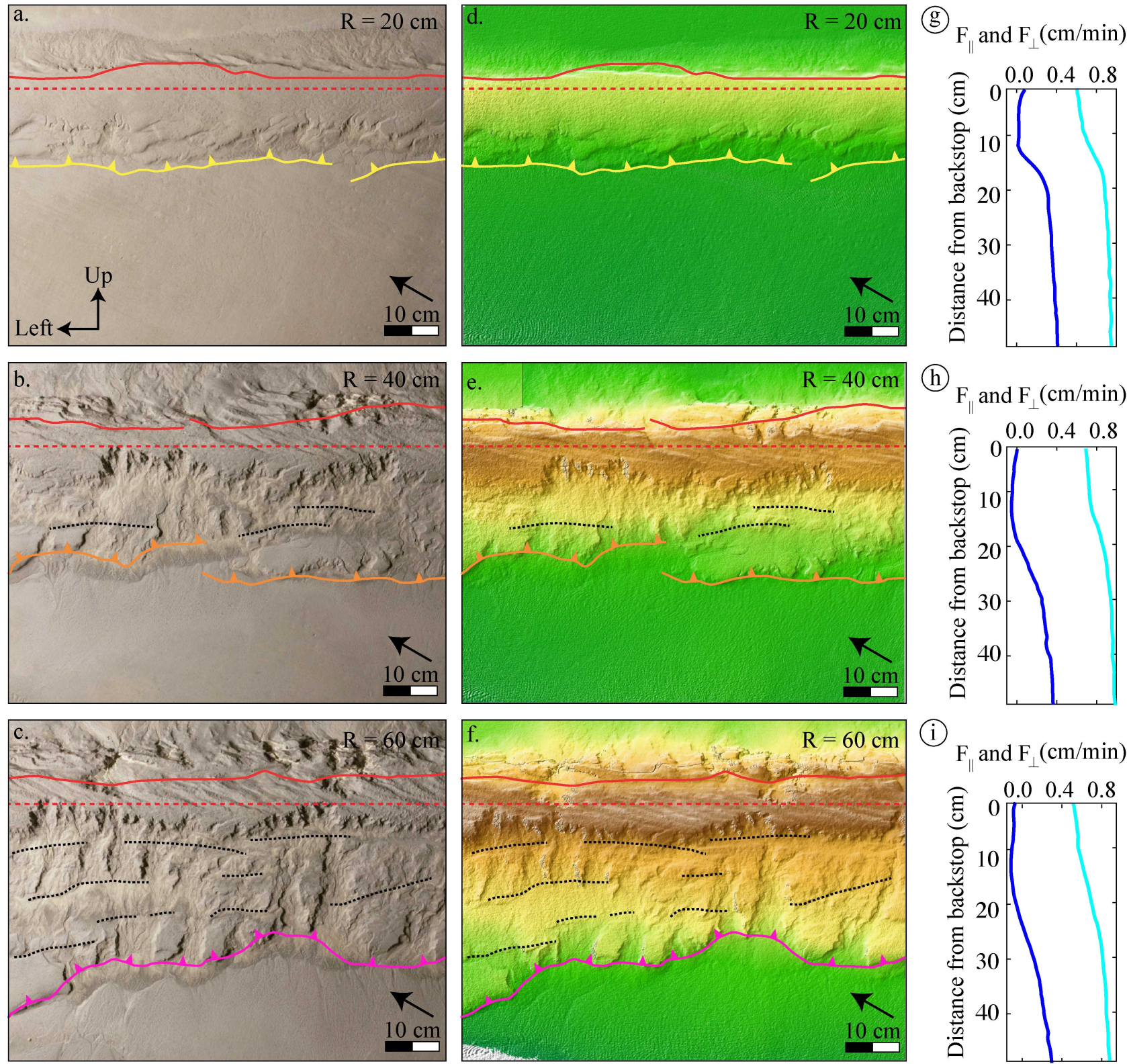

-... Thrust 1 - Secondary faults

— Main retro-fault at the surface

- - Velocity discontinuity at depth (backstop)

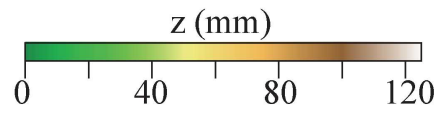

Velocity component

- Left-Right $\left(\mathrm{F}_{\|}\right)$

- Up-Down $\left(\mathrm{F}_{\perp}\right)$

FIGURE 3 - Evolution of the experimental orogenic wedge through time and associated average horizontal velocity field. Each picture $(a-c)$ and the associated DEM $(d-f)$ correspond to a shortening increment of $\sim 20 \mathrm{~cm}$. The average left-right (parallel to the velocity discontinuity) and up-down (perpendicular to the velocity discontinuity) components of the incremental horizontal velocity field are also presented $(g-i)$. The main thrusts are labelled in chronological order, from the first thrust ( $T 1$ in yellow) to the third one (T3 in magenta), the red line indicates the main retro-fault at the surface, the red dotted line indicates the position of the backstop at depth (i.e., of the velocity discontinuity), and the black arrow is the direction of crustal shortening (adapted from Guerit et al., 2016). This figure is available in color online at www.interscience.wiley.com/journal/espl. 


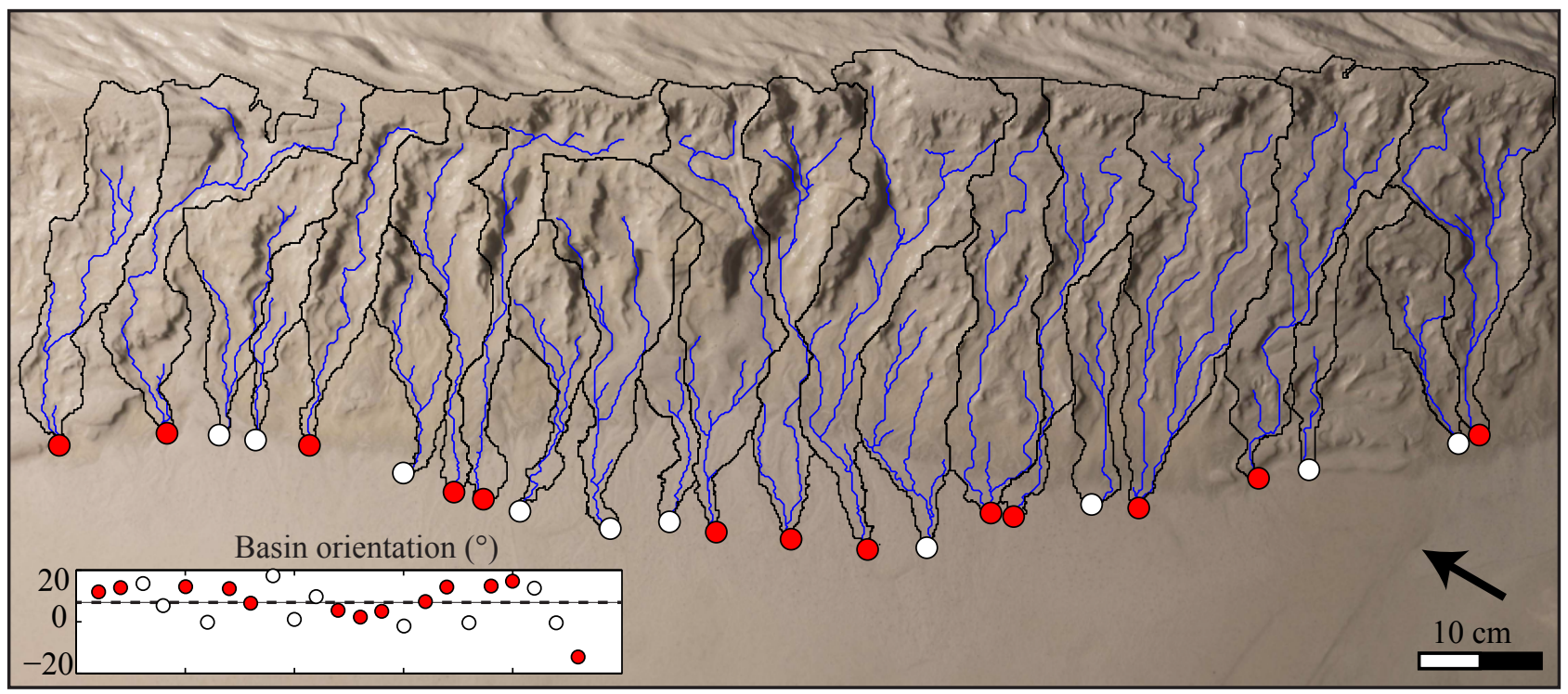

FIGURE 4 - Typical map of the drainage network extracted from one DEM with the streams in blue, the drainage basins in black, and the drainage basin orientation in the insert (a stream perpendicular to the orogen has an orientation of $\mathrm{O}^{\circ}$ ). Outlets of the large and small basins correspond to the red and white circles, respectively, and the imposed direction of crustal shortening is indicated by the black arrow. This figure is available in color online at www.interscience.wiley.com/journal/espl.

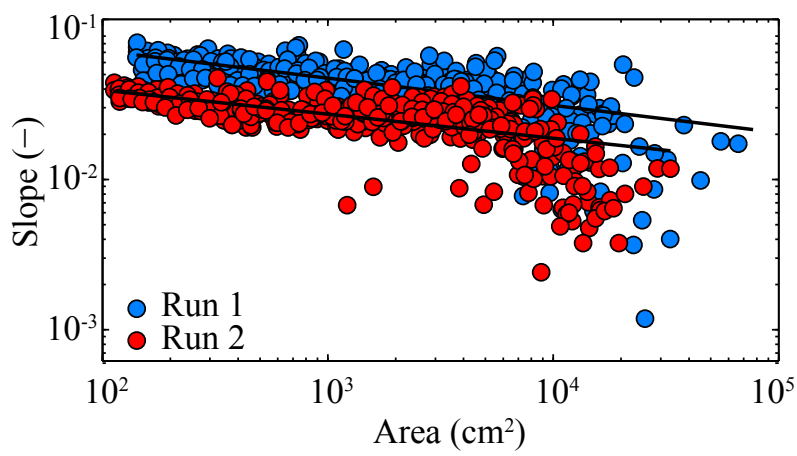

FIGURE 5 - Slope-area relationships for the two replicate runs analyzed in this study. The two runs feature the same $m / n$ ratio of 0.2, in good agreement with the coefficient derived from $\chi-z$ plots (Fig. S2). This figure is available in color online at www.interscience.wiley.com/journal/espl. 


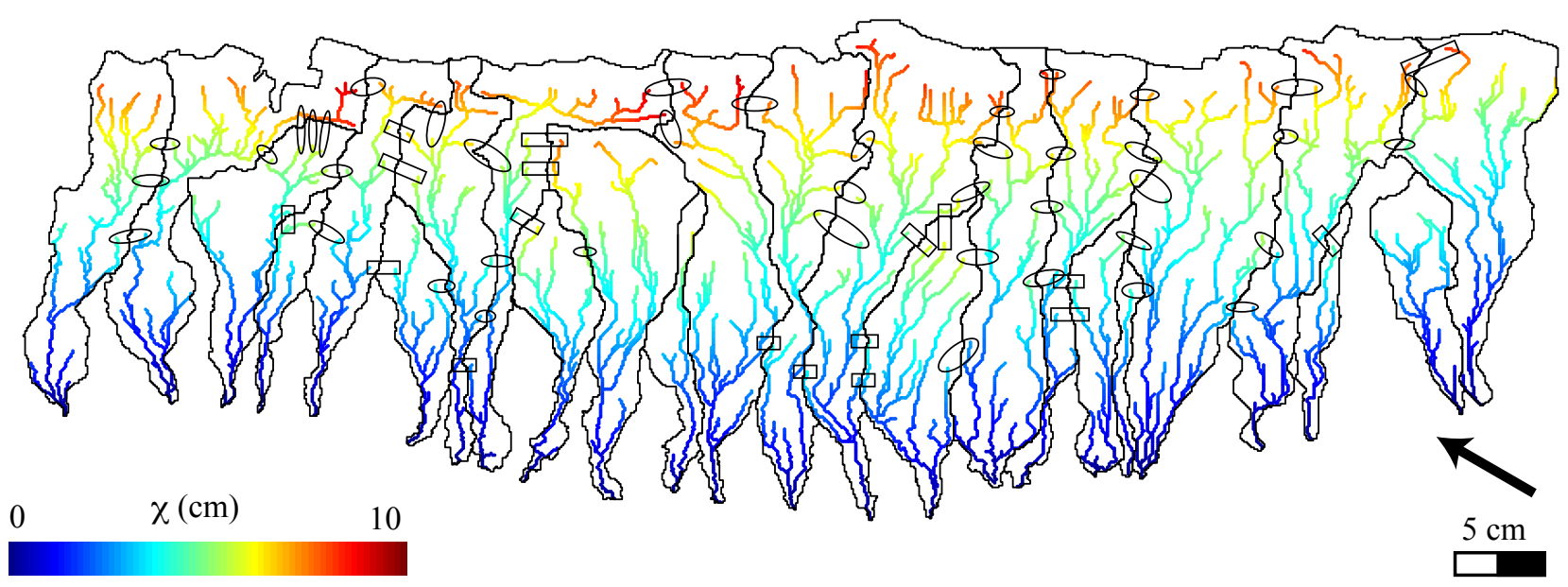

Figure 6 - Typical map of the $\chi$ distribution along the drainage network. The $\Delta \chi$ across divides are indicated by ellipses when the high $\chi$ value is on their left side, and by rectangles when the high $\chi$ value is on their right side. The black lines delineate the drainage basins and the black arrow indicates the direction of convergence. This figure is available in color online at www.interscience.wiley.com/journal/espl.

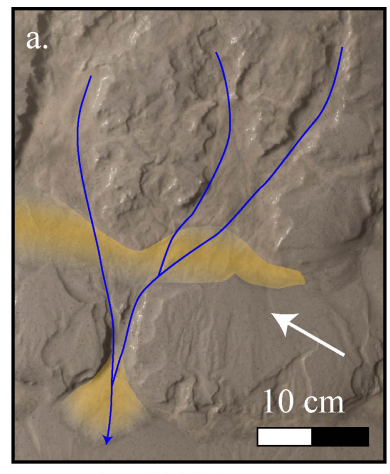

$\mathrm{R}=75.00 \mathrm{~cm}$

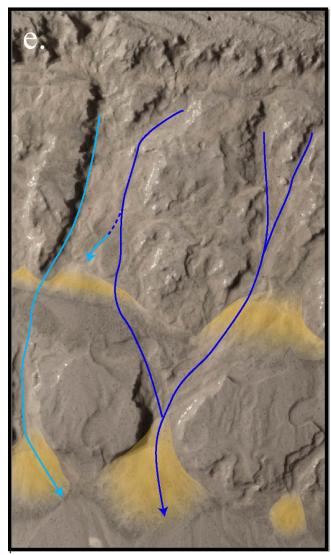

$\mathrm{R}=78.75 \mathrm{~cm}$

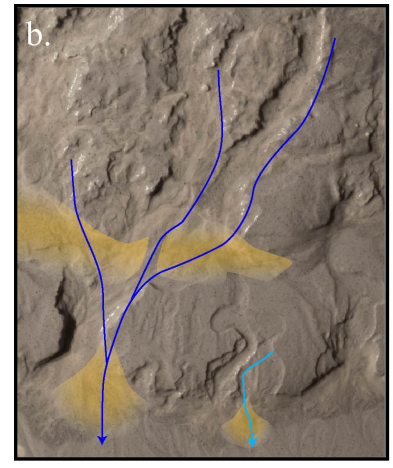

$\mathrm{R}=76.25 \mathrm{~cm}$

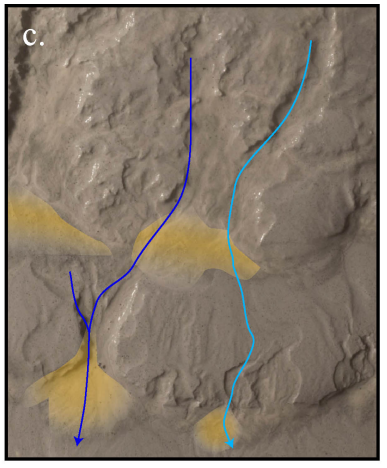

$\mathrm{R}=77.50 \mathrm{~cm}$

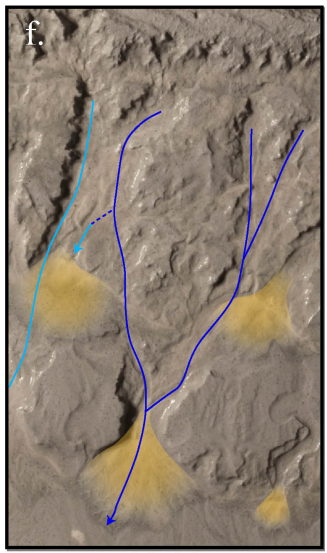

$\mathrm{R}=80.00 \mathrm{~cm}$

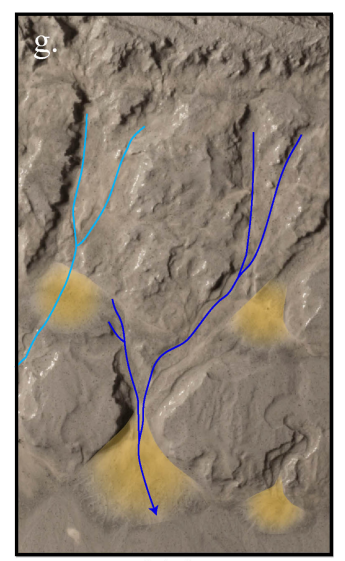

$\mathrm{R}=81.25 \mathrm{~cm}$

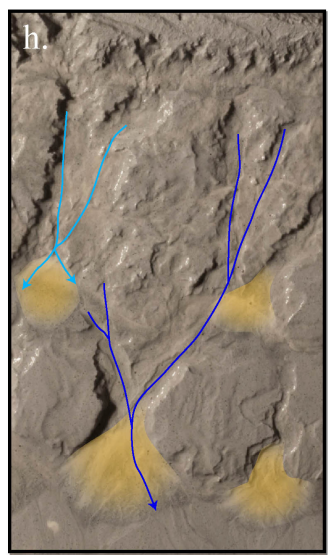

$\mathrm{R}=82.50 \mathrm{~cm}$

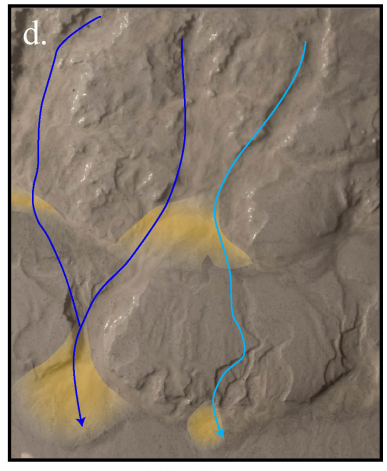

$\mathrm{R}=78.75 \mathrm{~cm}$

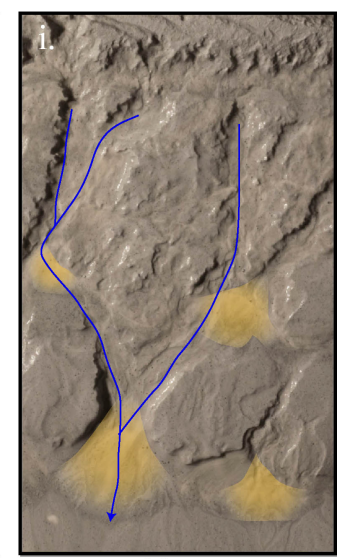

$\mathrm{R}=83.75 \mathrm{~cm}$

FIGURE 7 -Illustrations of drainage reorganizations occurring during the experiments. Drainage evolution seems to be favored by regressive erosion initiated at the front of the relief $(a-d)$ and by stream avulsion in alluvial areas (e-i). Pictures are taken every $1.25 \mathrm{~cm}$ of shortening, the imposed direction of convergence is indicated by the white arrow, the main flow paths are mapped in dark and light blue, and the areas of sediment deposition in orange. This figure is available in color online at www.interscience.wiley.com/journal/espl. 
(a)
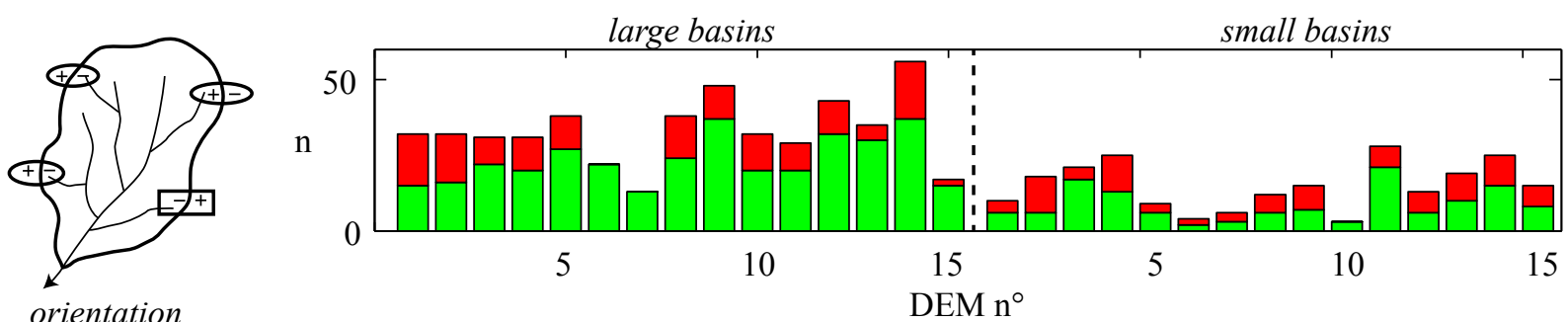

(b)

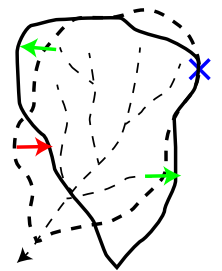

agreement with $\chi$

(c)
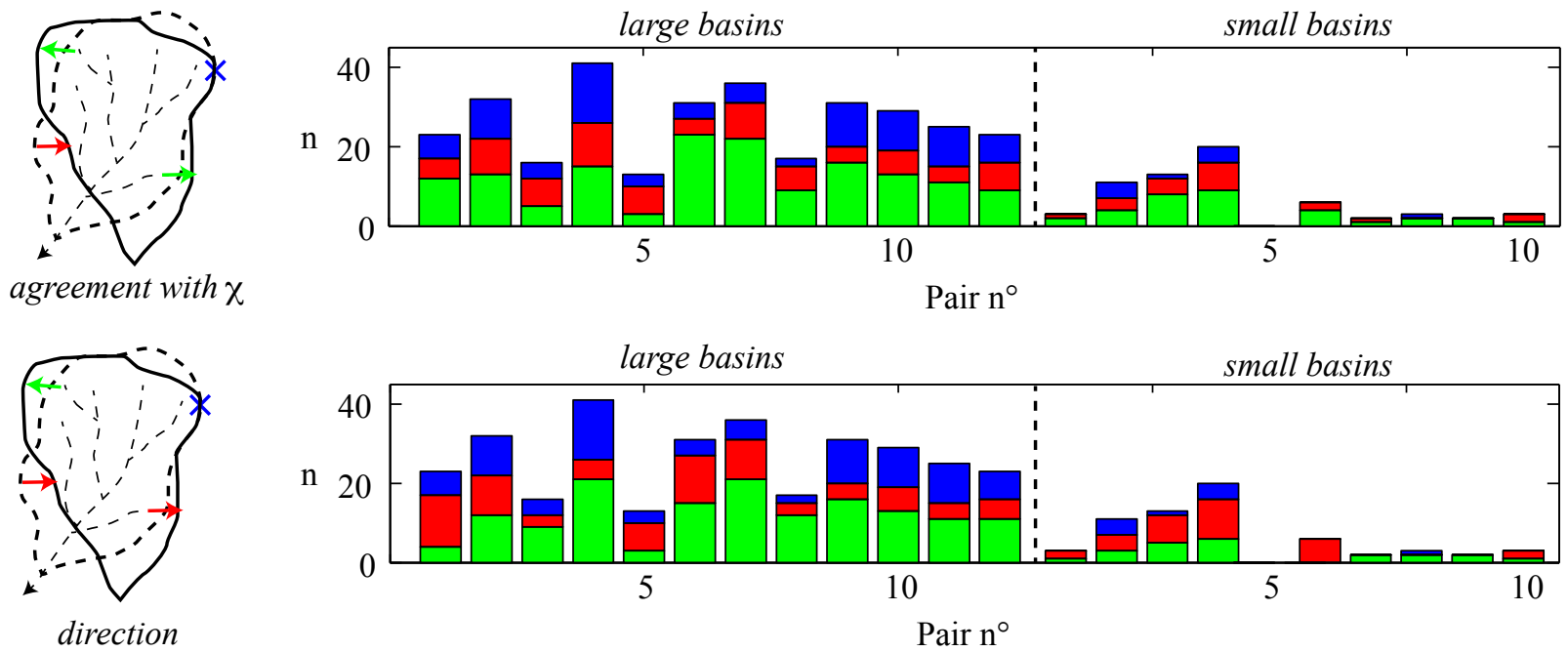

FIGURE 8 - Statistical analysis of the relation between the $\chi$ pattern and the drainage organization, for the large and the small basins. a) Orientation of $\Delta \chi$ at $T_{0}$. Green bars are for $\Delta \chi$ with the high value on the left side of the divide (mapped by ellipses), red bars are for $\Delta \chi$ with the low value on the left side of the divide (mapped by rectangles). b) Evolution between $T_{0}$ and $T_{1}$ of the divides affected by a $\Delta \chi$ at $T_{0}$, with respect to the $\Delta \chi$ orientation. Green is for divides that migrated toward the high $\chi$ value, red is for divides that migrated toward the low $\chi$ value and blue is for divides that did not evolve. c) Direction of migration between $T_{0}$ and $T_{1}$ of the divides affected by a $\Delta \chi$ at $T_{0}$. Green is for divides that migrated toward the left, red is for divides that migrated toward the right, and blue is for divides that did not evolve. This figure is available in color online at www.interscience.wiley.com/journal/espl. 


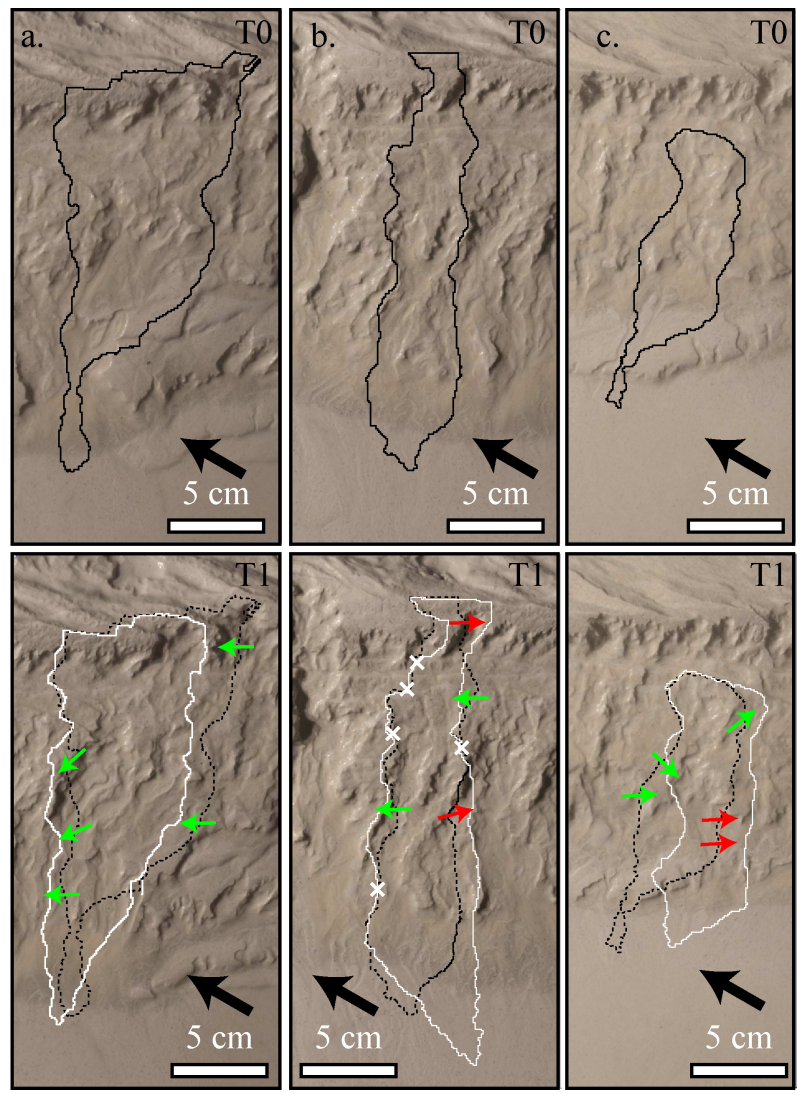

FIGURE 9 -Examples of the evolution of a), b) large and c) small basins between $T_{0}$ and $T_{1}$. Arrows are located where $\Delta \chi$ have been previously mapped and indicate the evolution of the basins edges: the green arrows are for the divide migrations in agreement with the $\Delta \chi$ at $T_{0}$, the red ones are for the divide migrations that are not in agreement with the $\Delta \chi$ at $T_{0}$, and the white crosses are for the areas that did not evolve significantly between the two DEMs. This figure is available in color online at www.interscience.wiley.com/journal/espl. 